\title{
Repair of Acute Type-A Aortic Dissection in the Present Era: Outcomes and Controversies
}

\author{
Ellie Moeller, BS ${ }^{1}$ Marcos Nores, $\mathrm{MD}^{1} \quad$ Sotiris C. Stamou, MD, $\mathrm{PhD}^{1}{ }^{10}$ \\ ${ }^{1}$ Department of Cardiothoracic Surgery, JFK Medical Center, \\ Atlantis, FL \\ Address for correspondence Sotiris C. Stamou, MD, PhD, Department \\ of Cardiothoracic Surgery, JFK Medical Center, 180 JFK Dr., Suite 320 , \\ Atlantis, FL 33462 (e-mail: cvsisfun@hotmail.com).
}

AORTA 2019;7:155-162.

\begin{abstract}
Acute Type-A aortic dissection (AAAD) remains a surgical emergency with a relatively high operative mortality despite advances in medical and surgical management over the past three decades. In spite of the severity of disease, there is a paucity of studies reviewing key controversies surrounding AAAD repair and management. A systematic literature search was performed using Cochrane review and PubMed bibliography review. Abstracts were first reviewed for general pertinence and then articles were reviewed in full. Literature review indicates that use of moderate hypothermia and antegrade cerebral perfusion is a safe alternative to deep hypothermia. In hemodynamically stable patients, axillary cannulation may be substituted for femoral cannulation. With regard to the technical aspects of repair, preserving the aortic root whenever possible and performing the distal anastomosis with the open distal technique rather

Keywords

- aortic dissection

- outcomes

- circulatory arrest

- pathophysiology

- adults than with the clamp on is the preferred approach. In patients with a patent false lumen, close monitoring is indicated. As demonstrated by the literature, significant improvement of early and late mortality over the past years has occurred in patients presenting with AAAD. Repair of acute Type-A aortic dissection remains a challenge with high operative mortality; however, improvement of surgical techniques and management have resulted in improvement of early and late clinical outcomes.
\end{abstract}

\section{Introduction}

Acute Type-A aortic dissection (AAAD) remains a surgical emergency with a relatively high operative mortality despite advances in medical and surgical management over the past three decades. ${ }^{1-3}$ Due to the prevalence and severity of the disease process, significant research exists surrounding the optimal management and expected outcomes of AAAD. ${ }^{4}$

However, underlying the extensive studies on this topic have several controversies regarding key topics of management. Specifically, topics including deep versus moderate hypothermia, cannulation site, technical aspects of repair, hemodynamic instability, and the fate of the false lumen are debated. There is a paucity of studies investigating the current status of these key topics. This review is necessary to explore and understand controversies surrounding AAAD management.

received

November 5, 2018 accepted after revision October 22, 2019
DOI https://doi.org/

10.1055/s-0039-3401810. ISSN 2325-4637.

\section{Methods}

A literature review was conducted using PubMed and. We aimed to review all studies on repair of Type-A aortic dissection using PubMed and Cochrane Library databases. Abstracts were first reviewed for general pertinence, and then articles were reviewed in full. Additional literature search was performed by reviewing the reference lists of articles. Our search process concluded in October 2018.

\section{Results}

\section{Deep Hypothermia versus Moderate Hypothermia}

Deep hypothermic circulatory arrest (DHCA) is considered by many experts to be the standard of care for surgical repair of AAAD. ${ }^{5,6}$ Deep hypothermia decreases brain metabolism by

Copyright $\odot 2019$ by Thieme Medical Publishers, Inc., 333 Seventh Avenue, New York, NY 10001, USA. Tel: +1(212) 760-0888.
License terms

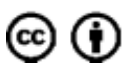


approximately $50 \%$ per $6^{\circ} \mathrm{C}$ drop in organ temperature and enables full neurologic recovery after the interval of interruption in brain perfusion. ${ }^{7,8}$ However, due to prolonged duration of cardiopulmonary bypass (CPB) typically associated with the profound hypothermia induced by DHCA, increased complication rates including postoperative bleeding, endothelial dysfunction, neuronal apoptosis, and postoperative pulmonary complications are reported to exist. ${ }^{5}$ In addition, DHCA induces vasoconstriction and decreases regional cerebral blood flow. ${ }^{5}$ The combination of complications and unfavorable physiologic changes associated with DHCA have led to a gradual shift toward using moderate degrees of hypothermia (MH). ${ }^{5}$

Recent studies have found $\mathrm{MH}$ to be independently associated with lower risk of mortality and major adverse cardiac and cardiovascular events during AAAD repair. ${ }^{5,9}$ A retrospective cohort study by Algarni et $\mathrm{al}^{5}$ of 128 patients compared the two strategies of cooling (DHCA, $\angle 20^{\circ} \mathrm{C}$; and $\mathrm{MH}, 22-28^{\circ} \mathrm{C}$ ) to repair AAAD at a single center, and their results are shown in - Table 1 . Algarni et $\mathrm{al}^{5}$ reported significantly higher rates of stroke with persistent neurologic deficit (21 and 13\%, $p=0.042$ ) and low cardiac output syndrome (26 and 5\%, $p<0.001$ ) in the DHCA group compared with the MH group, respectively. Mortality was almost two-fold higher in the DHCA group than the MH group (28 and $16 \%, p=0.07) .{ }^{5}$ However, in addition to these findings, CPB time and blood transfusion were significantly higher in the DHCA group than the MH group $(p=0.04)$.

These findings raise questions as to whether hypothermic temperature may also play a confounding role, as supported by a recent study by the senior author. ${ }^{10}$ We compared survival between 324 patients undergoing AAAD repair with either DHCA, retrograde, or anterograde cerebral perfusion. ${ }^{10}$ Using multivariable logistic regression, we found that independent predictors of operative mortality were hemodynamic instability and $\mathrm{CPB}$ time, not type of cerebral protection used. ${ }^{10}$ The strongest negative effect of DHCA originates from increased $\mathrm{CPB}$ times and subsequent length of operation in comparison with $\mathrm{MH} .{ }^{11-13}$ Extended CPB times during cardiac surgery are implicated in increased risk of acute renal insufficiency, stroke, and mortality. ${ }^{13-15}$ These effects can be compounded based on the condition of the patient. Diminished hematocrit and glyce- mic levels can increase perioperative risk during the use of CPB. ${ }^{16,17}$ In our study, the median CPB time was 219 minutes for the DHCA group and 173.5 minutes for the $\mathrm{MH}$ group $(p<0.001) .^{13}$ Also, the number of patients reaching the extended CPB time of 240 minutes in the DHCA group tripled that of the MH group $(p<0.015)$. An increased prevalence of postoperative risk found using DHCA might actually arise secondary to increase cardiopulmonary bypass times. ${ }^{13}$ However, limitations of moderate hypothermia may include higher risk of injury to the distal organs secondary to warmer temperatures, especially if body arrest time is prolonged. Further, patients who need more complex repairs, such as total aortic arch replacement may be better served by DHCA, or moderate hypothermia with dual perfusion of the brain via axillary artery and the body via the femoral artery.

Although additional studies are needed to investigate this controversy, $\mathrm{MH}$ with selective antegrade cerebral perfusion seems to be a safe strategy that accomplishes excellent outcomes with relatively low rate of neurologic complications and lower CPB times compared with DHCA. Both techniques, however, should aim toward limiting cardiopulmonary bypass times with efficient planning of the operative steps, such as completing the aortic root repair while cooling the patient to hypothermia.

\section{Axillary versus Femoral Cannulation}

Considerable debate remains regarding the optimal cannulation site in patients undergoing AAAD repair, specifically comparing clinical outcomes of axillary artery cannulation (AXC) with femoral artery cannulation (FAC). ${ }^{18-22}$ Concern of flow reversal in the thoracoabdominal aorta with FAC exists and has contributed to a trend of using the AXC site for $\mathrm{CPB}{ }^{23}$ Recent studies focus on early and late outcomes of $A X C$ versus FAC and inform the year-old controversy. ${ }^{18,20}$

A meta-analysis by Ren et al reviewed nine nonrandomized studies comparing outcomes in patients undergoing AAAD repair with AXC or FAC, with results shown in - Table $\mathbf{2}^{18}$ Fixed-effect modeling showed significantly lower incidence in short-term mortality (odds ratio $[\mathrm{OR}]=0.25$; 95\% confidence interval [CI]: $0.15-0.42 ; p<0.01)$ and in neurologic dysfunction $(\mathrm{OR}=0.46 ; 95 \% \mathrm{CI}: 0.29,0.72 ; p<0.01)$ in the AXC group.

Table 1 Summary of study findings on hypothermia

\begin{tabular}{|l|l|l|}
\hline Study & Patient & Finding \\
\hline Algarni et al $^{5}$ & $\begin{array}{l}\text { Risk of stroke, low cardiac output syndrome, } \\
\text { and mortality between medium } \\
\text { and deep hypothermia }\end{array}$ & $\begin{array}{l}\text { Significantly higher rates of stroke with persistent } \\
\text { neurologic deficit }(21 \text { and } 13 \%, p=0.042) \text { and low } \\
\text { cardiac output syndrome }(26 \text { and } 5 \%, p<0.001) \text { with } \\
\text { profound hypothermia compared with moderate. } \\
\text { Mortality was almost two-fold higher in the profound } \\
\text { group than the moderate group }(28 \text { and } 16 \%, p=0.07)\end{array}$ \\
\hline Stamou et al ${ }^{10}$ & $\begin{array}{l}\text { Survival rates of } 324 \text { patients undergoing } \\
\text { AAAD repair with either DHCA, retrograde } \\
\text { or anterograde cerebral perfusion }\end{array}$ & $\begin{array}{l}\text { No significance between types of cerebral protection } \\
\text { used. Predictors of operative mortality were } \\
\text { hemodynamic instability and CPB time }\end{array}$ \\
\hline Bakhtiary et al ${ }^{12}$ & $\begin{array}{l}\text { Clinical results of } 120 \text { patients undergoing } \\
\text { AAAD repair with mild systemic hypothermia }\end{array}$ & $\begin{array}{l}\text { Permanent neurologic deficits were seen in 4.2\% of } \\
\text { patients. The 30-day mortality rate was 5\%. } \\
\text { Follow-up of 2.8 years showed a survival rate of } 87 \%\end{array}$ \\
\hline
\end{tabular}

Abbreviations: AAAD, acute Type- A aortic dissection; CPB, cardiopulmonary bypass; DHCA, deep hypothermic circulatory arrest. 
Table 2 Meta-analysis results of axillary versus femoral cannulation

\begin{tabular}{|c|c|c|c|c|}
\hline Outcome & Odds ratio & Relative risk & 95\% confidence interval & p-Value \\
\hline \multicolumn{5}{|l|}{ Ren et al ${ }^{18}$ : } \\
\hline Short-term mortality & 0.25 & - & $0.15-0.42$ & 0.01 \\
\hline Neurologic dysfunction & 0.46 & & $0.29-0.72$ & 0.01 \\
\hline Malperfusion incidence & 0.84 & - & $0.37-1.90$ & 0.67 \\
\hline \multicolumn{5}{|l|}{ Benedetto et al ${ }^{23}$ : } \\
\hline In-hospital mortality & - & 0.59 & $0.48-0.7$ & $<0.01$ \\
\hline Permanent neurologic deficit & - & 0.71 & $0.55-0.9$ & 0.005 \\
\hline
\end{tabular}

Note: odds ratios and relative risk are shown as comparison of axillary/central artery cannulation versus femoral/peripheral artery cannulation.

A meta-analysis by Benedetto et $\mathrm{al}^{23}$ composed largely of retrospective studies, showed central cannulation, including the axillary artery, to be superior to peripheral cannulation of the femoral artery in the short term, as shown in - Table 2. These findings are hypothesized to be due to flow reversal in the thoracoabdominal aorta with femoral artery cannulation, increasing risk of brain or organ malperfusion. ${ }^{19,24}$ However, a recent study of 215 patients by Klotz et $\mathrm{al}^{25}$ found no significant differences in postoperative neurologic deficits ( $p=0.449)$ or 30 -day mortality $(p=0.699)$ between patients undergoing central and femoral cannulation. Despite this, most literature trends in favor of axillary cannulation, and most surgeons have adopted an antegrade perfusion strategy with axillary artery cannulation. ${ }^{26}$
With regard to long-term survival, data are limited. However, a retrospective study of 305 patients showed comparable 5-year survival between the axillary and femoral cannulation $(p=0.52) .{ }^{20}$ Cox's regression analysis demonstrated predictors of long-term mortality to be age $(p<0.001)$, stroke $(p<0.001)$, prolonged CPB time $(p=0.001)$, hemodynamic instability $(p=0.002)$, and renal failure $(p=0.001) .{ }^{20}$ Additional studies demonstrated similar findings, presenting evidence that repair with AXC reduces overall mortality and neurologic complications when compared with FAC. ${ }^{27-31}$ These findings are summarized in - Table 3.

Debate is maintained through the studies that found no difference in survival or complication rates between AXC and FAC. $^{32-34}$ However, despite this, majority of the evidence

Table 3 Summary of study findings on cannulation site

\begin{tabular}{|c|c|c|}
\hline Study & Patient & Finding \\
\hline Stamou et $\mathrm{al}^{20}$ & 5-year survival in patients undergoing $A X C$ vs. FAC & $\begin{array}{l}\text { No difference in 5-year survival between groups } \\
\text { undergoing AXC versus FAC }\end{array}$ \\
\hline Moizumi et al ${ }^{27}$ & $\begin{array}{l}\text { Pre- and postoperative predictors of hospital death } \\
\text { in patients with AAAD }\end{array}$ & $\begin{array}{l}\text { Vischeral ischemia }(\mathrm{OR}=18.4, p=0.0028) \text { and } \\
\text { absence of axillary artery perfusion }(\mathrm{OR}=8.2, \\
p=0.0014) \text { were independent preoperative and } \\
\text { operative predictors of hospital death }\end{array}$ \\
\hline Reuthebuch et $\mathrm{al}^{28}$ & $\begin{array}{l}\text { Clinical and neurological outcomes of patients } \\
\text { undergoing subclavian artery cannulation versus } \\
\text { femoral artery cannulation }\end{array}$ & $\begin{array}{l}\text { Significantly improved neurological outcome } \\
(p=0.0057) \text {, decreased postoperative bleeding } \\
(p<0.0001) \text {, decreased incidence of MI } \\
(p<0.0001) \text {, and decreased } 30 \text {-day mortality } \\
(p=0.0179) \text { in patients undergoing subclavian } \\
\text { artery cannulation compared with FAC }\end{array}$ \\
\hline Pasic et $\mathrm{al}^{30}$ & $\begin{array}{l}\text { Neurological complications and hospital mortality } \\
\text { in patients undergoing AAAD repair with AXC } \\
\text { versus FAC }\end{array}$ & $\begin{array}{l}\text { Postoperative complications occurred in both } \\
\text { groups, at nonsignificantly higher rates in FAC } \\
\text { compared with AXC }\end{array}$ \\
\hline Etz et $\mathrm{al}^{31}$ & $\begin{array}{l}\text { Mortality and stroke in patients undergoing AAAD } \\
\text { repair with AXC versus FAC }\end{array}$ & $\begin{array}{l}\text { AXC had significantly better outcomes than FAC } \\
(p=0.02)\end{array}$ \\
\hline Benedetto et $\mathrm{al}^{23}$ & $\begin{array}{l}\text { Meta-analysis of } 4,476 \text { patients comparing central } \\
\text { and peripheral cannulation in patients undergoing } \\
\text { aortic surgery }\end{array}$ & $\begin{array}{l}\text { Central cannulation }(A X C) \text { showed decreased } \\
\text { in-hospital mortality }(R R=0.59, p<0.001) \text { and } \\
\text { permanent neurological dysfunction }(R R=0.71 \text {, } \\
p=0.005) \text { when compared with peripheral } \\
\text { cannulation (FAC) }\end{array}$ \\
\hline Klotz et $\mathrm{al}^{25}$ & $\begin{array}{l}\text { Postoperative cerebral infarction, dialysis, and } \\
\text { 30-day mortality in patients undergoing AAAD } \\
\text { repair with either AXC or FAC }\end{array}$ & $\begin{array}{l}\text { Comparable postoperative cerebral infarction and } \\
\text { 30-day mortality between the groups }(p=0.699) \text {. } \\
\text { Nonsignificantly higher rates of need for dialysis in } \\
\text { patients undergoing FAC }(p=0.073)\end{array}$ \\
\hline
\end{tabular}

Abbreviations: AAAD, acute Type- A aortic dissection; AXC, axillary artery cannulation; FAC, femoral artery cannulation; OR, odds ratio; RR, risk ratio. 
demonstrates that perfusion through the AXC site may be clinically advantageous to FAC. Furthermore, these findings demonstrate that, regardless of cannulation strategy adopted, it is critical to carefully monitor procedures and respond adequately to adverse events. ${ }^{26}$

\section{Direct Aortic Cannulation}

This technique, which also avoids retrograde flow in the downstream aorta, is an alternative to time-consuming axillary artery access. The Hannover group reported their experience of direct aortic cannulation in 122 patients with aortic dissection. ${ }^{35}$ Malperfusion occurred in three patients (2.5\%). Hospital mortality was $15 \%$ for the entire cohort (18 patients). Permanent neurological dysfunction was detected in 15 patients (12\%), whereas temporary neurological dysfunction occurred in 21 (17\%). Total arch replacement was performed in 31 patients (25\%).

\section{Technical Aspects of Repair}

An additional area of controversy within AAAD repair is the different techniques of proximal and distal root reconstruction. Choice of reconstruction technique is largely based on viability and function of affected tissue; however, perioperative outcomes are poorly studied. ${ }^{36}$ Importantly, surgeon preference may play a role in which technique is utilized, and it is therefore essential to fully understand the risk of each technique.

The most common surgical techniques for proximal root reconstruction include aortic valve $(\mathrm{AV})$ resuspension for structurally normal valves and sinuses, aortic valve replacement (AVR) for a structurally abnormal valve but intact sinuses, and root replacement if both the valve and sinuses are abnormal. ${ }^{36}$ A retrospective cohort study by Gunn et $\mathrm{al}^{37}$ found that the actuarial 10-year survival rates were greatest in AV resuspension, followed by root replacement and AVR (72, 56, and $36 \%$, respectively), and were significantly increased in patients who underwent AV resuspension as compared with AVR $(p=0.011)$. This finding is consistent with the premise that increasingly compromised tissue predisposes to greater risk. Gunn et al also showed independent predictors of operative mortality to be hemodynamic instability $(\mathrm{OR}=1.9 ; 95 \% \mathrm{CI}: 0.03,0.75 ; p=0.021)$ and $\mathrm{CPB}$ time greater than 200 minutes $(\mathrm{OR}=1.9 ; 95 \% \mathrm{CI}$ : 0.04, 0.54; $p=0.004$ ). Again, consistent with the extent of abnormalities, CPB was significantly longer in root replacement compared with AV resuspension $(p<0.001)$ or $\operatorname{AVR}(p=0.027){ }^{36}$
While most surgical repair focuses on proximal repairs as described previously, the dissection often propagates beyond the arch to the aortic bifurcation, described as a DeBakey-I dissection. Among proximal strategy repairs, most patients are left with a patent "Type-B" dissection, or false lumen, which yields a reoperation rate of more than $30 \%$ to address a dissecting aneurysm. To address this, standard proximal repair may be supplemented by thoracic stent-grafting through the open arch. A study by Pochettino et $\mathrm{al}^{38}$ demonstrated that antegrade stent graft deployment in patients with DeBakey-I dissections obliterated the false lumen in $80 \%$ of patients. Furthermore, short-term results were comparable between the stented and nonstented groups, despite longer CPB times in the stented group. In patients with DeBakey-I dissections; therefore, consideration of antegrade stent grafting should be given to lower morbidity and mortality.

With regard to construction of the distal anastomosis, open distal anastomosis under circulatory arrest or distal aortic clamping with hypothermic cardiopulmonary bypass are the primary surgical approaches. Recent studies comparing techniques demonstrate comparable outcomes and survivals. ${ }^{39-44}$ Although outcomes are similar, distal aortic clamping has been reported to distort the posterior tip of the clamp and does not allow resection of the injured clamping site, both of which may lead to higher reoperation for bleeding rates. ${ }^{45}$ As such, open distal anastomosis under circulatory arrest is preferred technically. ${ }^{46}$

\section{Hemodynamic Instability}

Although previous studies related hemodynamic instability to differences in early and late outcomes following AAAD, no studies have previously quantified late survival between hemodynamically stable and unstable patients. ${ }^{47} \mathrm{~A}$ recent study by Conway et $\mathrm{al}^{48}$ was consistent with prior findings, as shown in - Table $\mathbf{4}$. This study demonstrated significantly higher rates of postoperative complications in patients with hemodynamic instability, including cardiac arrest $(p<0.001)$, operative mortality $(p<0.001)$, and acute renal failure $(p=0.001)$. Late survival followed a similar trend, with decreased late survival among patients presenting with hemodynamic instability. At 1 year, $82 \%$ of hemodynamically stable patients and $57 \%$ of hemodynamically unstable patients were alive, and at 10 years, 63 and $44 \%$ patients, respectively. ${ }^{48}$ From these studies, the authors found that excessive mortality occurs early in the postoperative course in patients presenting

Table 4 Summary of study findings on surgical era

\begin{tabular}{|l|l|l|}
\hline Study & Patient & Finding \\
\hline Fann et al $^{76}$ & $\begin{array}{l}\text { Surgical survival rates of patients with AAAD } \\
\text { between } 1963 \text { and } 1992\end{array}$ & $\begin{array}{l}\text { Earlier operative year, hypertension, cardiac } \\
\text { tamponade, renal dysfunction, and older age were } \\
\text { independent determinants of operative death. }\end{array}$ \\
\hline Conway et al $^{77}$ & $\begin{array}{l}\text { Early postoperative outcomes and actuarial-free } \\
\text { survival in patients undergoing AAAD repair } \\
\text { between } 2000 \text { and } 2005 \text { and } 2006 \text { and 2010 }\end{array}$ & $\begin{array}{l}\text { Operative mortality was significantly higher in earlier } \\
\text { surgical era (24\% in 2000-2005, 12\% in 2006-2010; } \\
\text { p=0.013). Earlier date of surgery, hemodynamic } \\
\text { instability, and CPB }>200 \text { minutes were independent } \\
\text { determinants of operative mortality }\end{array}$ \\
\hline
\end{tabular}

Abbreviations: AAAD, acute Type- A aortic dissection; CPB, cardiopulmonary bypass. 
with hemodynamic instability. As such, treatment of these patients must be individualized.

Malperfusion syndromes include cardiac, cerebral, renal, mesenteric, iliofemoral, innominate, and spinal and are associated with high hospital mortality and increased postoperative complications. ${ }^{49,50}$ A study of 221 AAAD patients by Geirsson et $\mathrm{al}^{51}$ found malperfusion in $26.7 \%$ of patients, with more than $30 \%$ of these patients experiencing two or more malperfusion syndromes. Cardiac $(p=0.02)$ and cerebral malperfusions $(p<0.001)$ were significant risk factors for in-hospital mortality, and cerebral malperfusion was a significant risk factor for decreased long-term survival $(p=0.0002)$. Recommended treatment of malperfusion syndromes is rapid restoration of flow into the true lumen and obliteration of the false lumen to restore flow to all distal aortic branches.

In patients who are high risk for open repair, including those with significant comorbidities or anatomic challenges, endovascular treatment may provide an alternative. Although reports of endovascular repair are typically limited by small sample size, studies have shown promising outcomes for in-hospital and 30-day mortality rates. A study by Vallabhajosyula et $\mathrm{al}^{52}$ demonstrated zero in-hospital and 30-day mortality in patients treated endovascularly who were prohibited from open repair due to hemodynamic instability, extreme frailty, malignancy, and severe fibrosis or osteomyelitis of the mediastinum. Similar studies reported comparable outcomes in small series. ${ }^{53-56}$ These studies demonstrate that in patients who are hemodynamically unstable, have prohibitive comorbidities, or present anatomical challenges, endovascular repair of the ascending aorta is technically feasible. Although feasible in small series this technique is challenging and is presently not an acceptable treatment of Type-A aortic dissection.

\section{Fate of the False Lumen}

Persistent patent false lumen in the aorta is common in AAAD and may be associated with poor long-term prognosis. ${ }^{57-72}$

Analysis of the natural history of the residual aorta after AAAD repair provides insight into the outcomes for patients with persistent patent false lumen. The presence of a patent false lumen has been shown to be a significant risk factor for aortic enlargement, increasing the likelihood for reoperation. ${ }^{73}$ These findings are consistent with those of Park et $\mathrm{al}^{62}$ who found that the primary indication for reoperation following AAAD repair was progressive enlargement of the false lumen, affecting $43 \%$ of patients. Enlarged aortic diameter has been shown to be an independent predictor for chronic dissection. ${ }^{74}$ In addition to aortic enlargement, patent false lumen can lead to multiple reentries between the false and true lumen which requires reintervention, as described by Rylski et al. ${ }^{75}$ Endovascular repair may be used to seal the entry between the true and false lumen to decrease the blood flow through the false lumen and promote stabilization through thrombosis in the descending aorta. Additionally, in patients with DeBakey-I dissections, antegrade thoracic stent grafting can be utilized to obliterate the false lumen in up to $80 \%$ of patients, as described by
Pochettino et al. ${ }^{38}$ Endovascular interventions have been shown to be well tolerated with antegrade stent graft deployment being a safe method to obliterate the thoracic false lumen. This type of "elephant trunk" thoracic stentgrafting provides equivocal short-term results compared with standard, open repair and lowers morbidity and mortality in the long-term.

Given the increased risk of aortic enlargement, reentry, and chronic dissection, it is indicated to monitor patients with a patent false lumen more closely to assess lumen status. Furthermore, select patient groups may benefit from endovascular repair or supplemental stent grafting.

\section{Outcomes in the Current Era}

The culmination of previously discussed controversies is an analysis of the clinical outcomes following repair over time. A previous study described a decline in operative mortality over the period from 1963 to 1992, with findings summarized in - Table 4 . $^{76}$ However, with broad understanding of disease and advances in surgical technique, how has the survival trend changed in the current era?

To address this question, Conway et $\mathrm{al}^{77}$ compared 111 patients who underwent repair between 2000 and 2005 with 140 patients who underwent repair between 2006 and 2010 . This study demonstrated that operative mortality was significantly influenced by surgical era, with a $24 \%$ operative mortality rate in patients treated between 2000 and 2005 compared with $12 \%$ in patients treated between 2006 and 2010 ( $p=0.013$ ). Independent predictors of operative mortality as described by multivariate logistic regression included hemodynamic instability $(\mathrm{OR}=17.8 ; 95 \% \mathrm{CI}$ : $0.05-0.35$; $p<0.001)$, СРВ time $>200$ minutes $\quad(\mathrm{OR}=9.5,95 \% \mathrm{CI}$ : $0.14-0.64 ; p=0.002)$, and earlier date of surgery ( $\mathrm{OR}=5.8$; $95 \%$ CI: $1.18,5.14 ; p=0.016$ ). Additionally, actuarial 5-year survival was significantly worse for patients treated earlier (64\% for $2000-2005,77 \%$ for $2006-2010, p<0.001$ ). ${ }^{77}$ These findings demonstrate that the early clinical outcomes of repair of Type A aortic dissection have improved over time.

\section{Conclusions}

A long history of research on AAAD repair demonstrates significant progress. However, the literature also exposes areas of controversy. Current literature review indicates that use of moderate hypothermia and antegrade cerebral perfusion is a safe alternative to deep hypothermia. Furthermore, axillary cannulation maybe used instead of femoral artery in hemodynamically stable patients who don't require emergent institution of cardiopulmonary bypass. Challenges still include the treatment of the hemodynamically unstable patients, as well as those with malperfusion. With regard to the technical aspects of repair, preserving the aortic root whenever possible, and performing the distal anastomosis with the open distal technique rather than with the clamp on is the preferred approach. In patients with a patent false lumen, close monitoring is indicated. As demonstrated by the literature, significant improvement of early and late mortality over the past years has occurred in patients presenting with AAAD. 


\section{Funding}

This research was supported (in whole or in part) by HCA Healthcare and/or an HCA Healthcare affiliated entity. The views expressed in this publication represent those of the author(s) and do not necessarily represent the official views of HCA Healthcare or any of its affiliated entities.

\section{Conflict of Interest}

The authors declare no conflict of interest related to this article.

\section{Acknowledgment}

None.

\section{References}

1 Conway BD, Stamou SC, Kouchoukos NT, Lobdell KW, Hagberg RC. Effects of gender on outcomes and survival following repair of acute type A aortic dissection. Int J Angiol 2015;24(02):93-98

2 Tolis G Jr, Sundt TM III. Contemporary insights into the management of type A aortic dissection. Expert Rev Cardiovasc Ther 2016;14(10):1189-1196

3 Skripochnik E, Friedman P, Michler RE, Neragi-Miandoab S. The outcome of surgical management of type A aortic dissection. Asian Cardiovasc Thorac Ann 2014;22(06):687-693

4 Pape LA, Awais M, Woznicki EM, et al. Presentation, diagnosis, and outcomes of acute aortic dissection: 17-year trends from the International Registry of Acute Aortic Dissection. J Am Coll Cardiol 2015;66(04):350-358

5 Algarni KD, Yanagawa B, Rao V, Yau TM. Profound hypothermia compared with moderate hypothermia in repair of acute type $A$ aortic dissection. J Thorac Cardiovasc Surg 2014;148(06): 2888-2894

6 Griepp RB, Stinson EB, Hollingsworth JF, Buehler D. Prosthetic replacement of the aortic arch. J Thorac Cardiovasc Surg 1975;70 (06):1051-1063

7 Gega A, Rizzo JA, Johnson MH, Tranquilli M, Farkas EA, Elefteriades JA. Straight deep hypothermic arrest: experience in 394 patients supports its effectiveness as a sole means of brain preservation. Ann Thorac Surg 2007;84(03):759-766, discussion 766-767

8 Percy A, Widman S, Rizzo JA, Tranquilli M, Elefteriades JA. Deep hypothermic circulatory arrest in patients with high cognitive needs: full preservation of cognitive abilities. Ann Thorac Surg 2009;87(01):117-123

9 Numata S, Tsutsumi Y, Monta O, et al. Acute type A aortic dissection repair with mild-to-moderate hypothermic circulatory arrest and selective cerebral perfusion. J Cardiovasc Surg (Torino) 2015;56(04):525-530

10 Stamou SC, Rausch LA, Kouchoukos NT, et al. Comparison between antegrade and retrograde cerebral perfusion or profound hypothermia as brain protection strategies during repair of type A aortic dissection. Ann Cardiothorac Surg 2016;5(04): 328-335

11 Ueda Y. What is the best method for brain protection in surgery of the aortic arch? Retrograde cerebral perfusion. Cardiol Clin 2010; 28(02):371-379

12 Bakhtiary F, Dogan S, Zierer A, et al. Antegrade cerebral perfusion for acute type A aortic dissection in 120 consecutive patients. Ann Thorac Surg 2008;85(02):465-469

13 Stamou SC, McHugh MA, Conway BD, Nores M. Role of moderate hypothermia and antegrade cerebral perfusion during repair of type a aortic dissection. Int J Angiol 2018;27(04):190-195

14 McKhann GM, Goldsborough MA, Borowicz LM Jr, et al. Predictors of stroke risk in coronary artery bypass patients. Ann Thorac Surg 1997;63(02):516-521
15 Halkos ME, Kerendi F, Myung R, Kilgo P, Puskas JD, Chen EP. Selective antegrade cerebral perfusion via right axillary artery cannulation reduces morbidity and mortality after proximal aortic surgery. J Thorac Cardiovasc Surg 2009;138(05): 1081-1089

16 Doenst T, Wijeysundera D, Karkouti K, et al. Hyperglycemia during cardiopulmonary bypass is an independent risk factor for mortality in patients undergoing cardiac surgery. J Thorac Cardiovasc Surg 2005;130(04):1144

17 Karkouti K, Djaiani G, Borger MA, et al. Low hematocrit during cardiopulmonary bypass is associated with increased risk of perioperative stroke in cardiac surgery. Ann Thorac Surg 2005; 80(04):1381-1387

18 Ren Z, Wang Z, Hu R, et al. Which cannulation (axillary cannulation or femoral cannulation) is better for acute type A aortic dissection repair? A meta-analysis of nine clinical studies. Eur J Cardiothorac Surg 2015;47(03):408-415

19 Tiwari KK, Murzi M, Bevilacqua S, Glauber M. Which cannulation (ascending aortic cannulation or peripheral arterial cannulation) is better for acute type A aortic dissection surgery? Interact Cardiovasc Thorac Surg 2010;10(05):797-802

20 Stamou SC, Gartner D, Kouchoukos NT, et al. Axillary versus femoral arterial cannulation during repair of type A aortic dissection?: an old problem seeking new solutions Aorta (Stamford) 2016;4(04):115-123

21 Neri E, Massetti M, Capannini G, et al. Axillary artery cannulation in type a aortic dissection operations. J Thorac Cardiovasc Surg 1999;118(02):324-329

22 Kokotsakit J, Lazopoulos G, Milonakis M, et al. Right axillary artery cannulation for surgical management of the hostile ascending aorta. Tex Heart Inst J 2005;32(02):189-193, discussion 185

23 Benedetto U, Raja SG, Amrani M, et al. The impact of arterial cannulation strategy on operative outcomes in aortic surgery: evidence from a comprehensive meta-analysis of comparative studies on 4476 patients. J Thorac Cardiovasc Surg 2014; 148(06): 2936-43.e1, 4

24 Gulbins H, Pritisanac A, Ennker J. Axillary versus femoral cannulation for aortic surgery: enough evidence for a general recommendation? Ann Thorac Surg 2007;83(03):1219-1224

25 Klotz S, Heuermann K, Hanke T, Petersen M, Sievers HH. Outcome with peripheral versus central cannulation in acute type A dissection. Interact Cardiovasc Thorac Surg 2015;20(06):749-753, discussion 754

26 Abe T, Usui A. The cannulation strategy in surgery for acute type A dissection. Gen Thorac Cardiovasc Surg 2017;65(01):1-9

27 Moizumi Y, Motoyoshi N, Sakuma K, Yoshida S. Axillary artery cannulation improves operative results for acute type a aortic dissection. Ann Thorac Surg 2005;80(01):77-83

28 Reuthebuch O, Schurr U, Hellermann J, et al. Advantages of subclavian artery perfusion for repair of acute type A dissection. Eur J Cardiothorac Surg 2004;26(03):592-598

29 Orihashi K. Malperfusion in acute type a aortic dissection: unsolved problem. Ann Thorac Surg 2013;95(05):1570-1576

30 Pasic M, Schubel J, Bauer M, et al. Cannulation of the right axillary artery for surgery of acute type A aortic dissection. Eur J Cardiothorac Surg 2003;24(02):231-235, discussion 235-236

31 Etz CD, Plestis KA, Kari FA, et al. Axillary cannulation significantly improves survival and neurologic outcome after atherosclerotic aneurysm repair of the aortic root and ascending aorta. Ann Thorac Surg 2008;86(02):441-446, discussion 446-447

32 Lee HK, Kim GJ, Cho JY, Lee JT, Park I, Lee YO. Comparison of the outcomes between axillary and femoral artery cannulation for acute type A aortic dissection. Korean J Thorac Cardiovasc Surg 2012;45(02):85-90

33 Sadi L, Tønnessen T, Pillgram-Larsen J. Short and long-term survival in type A aortic dissection justifies the operative risk and effort. Scand Cardiovasc J 2012;46(01):45-50 
34 Etz CD, von Aspern K, da Rocha E Silva J, et al. Impact of perfusion strategy on outcome after repair for acute type a aortic dissection. Ann Thorac Surg 2014;97(01):78-85

35 Khaladj N, Shrestha M, Peterss S, et al. Ascending aortic cannulation in acute aortic dissection type A: the Hannover experience. Eur J Cardiothorac Surg 2008;34(04):792-796, 796

36 Krüger T, Conzelmann LO, Bonser RS, et al. Acute aortic dissection type A. Br J Surg 2012;99(10):1331-1344

37 Gunn TM, Stamou SC, Kouchoukos NT. Techniques of Proximal Root Reconstruction and Outcomes Following Repair of Acute Type A Aortic Dissection. Aorta (Stamford) 2016;4(02):33-41

38 Pochettino A, Brinkman WT, Moeller P, et al. Antegrade thoracic stent grafting during repair of acute DeBakey I dissection prevents development of thoracoabdominal aortic aneurysms. Ann Thorac Surg 2009;88(02):482-489, discussion 489-490

39 Danner BC, Natour E, Horst M, Dikov V, Ghosh PK, Dapunt OE. Comparison of operative techniques in acute type A aortic dissection performing the distal anastomosis. J Card Surg 2007;22(02): 105-110

40 Lai DT, Miller DC, Mitchell RS, et al. Acute type A aortic dissection complicated by aortic regurgitation: composite valve graft versus separate valve graft versus conservative valve repair. J Thorac Cardiovasc Surg 2003;126(06):1978-1986

41 Moon MR, Sundt TM III, Pasque MK, et al. Does the extent of proximal or distal resection influence outcome for type A dissections? Ann Thorac Surg 2001;71(04):1244-1249, discussion 1249-1250

42 Pansini S, Gagliardotto PV, Pompei E, et al. Early and late risk factors in surgical treatment of acute type A aortic dissection. Ann Thorac Surg 1998;66(03):779-784

43 Pessotto R, Santini F, Pugliese P, et al. Preservation of the aortic valve in acute type $A$ dissection complicated by aortic regurgitation. Ann Thorac Surg 1999;67(06):2010-2013, discussion 20142019

44 Ehrlich MP, Ergin MA, McCullough JN, et al. Results of immediate surgical treatment of all acute type A dissections. Circulation 2000;102(19, Suppl 3):III248-III252

45 Elefteriades JA. What operation for acute type A dissection? J Thorac Cardiovasc Surg 2002;123(02):201-203

46 Stamou SC, Kouchoukos NT, Hagberg RC, et al. Does the technique of distal anastomosis influence clinical outcomes in acute type A aortic dissection? Interact Cardiovasc Thorac Surg 2011;12(03): 404-408

47 Trimarchi S, Nienaber CA, Rampoldi V, et al; International Registry of Acute Aortic Dissection Investigators. Contemporary results of surgery in acute type A aortic dissection: The International Registry of Acute Aortic Dissection experience. J Thorac Cardiovasc Surg 2005;129(01):112-122

48 Conway BD, Stamou SC, Kouchoukos NT, et al. Effects of hemodynamic instability on early outcomes and late survival following repair of acute type A aortic dissection. Aorta (Stamford) 2014;2 (01):22-27

49 Kawahito K, Adachi H, Murata S, Yamaguchi A, Ino T. Coronary malperfusion due to type A aortic dissection: mechanism and surgical management. Ann Thorac Surg 2003;76(05):1471-1476, discussion 1476

50 Neri E, Toscano T, Papalia U, et al. Proximal aortic dissection with coronary malperfusion: presentation, management, and outcome. J Thorac Cardiovasc Surg 2001;121(03):552-560

51 Geirsson A, Szeto WY, Pochettino A, et al. Significance of malperfusion syndromes prior to contemporary surgical repair for acute type A dissection: outcomes and need for additional revascularizations. Eur J Cardiothorac Surg 2007;32(02):255-262

52 Vallabhajosyula P, Gottret JP, Bavaria JE, Desai ND, Szeto WY. Endovascular repair of the ascending aorta in patients at high risk for open repair. J Thorac Cardiovasc Surg 2015;149(2, Suppl) S144-S150
53 Kolvenbach RR, Karmeli R, Pinter LS, et al. Endovascular management of ascending aortic pathology. J Vasc Surg 2011;53(05): 1431-1437

54 Pires de Morais G, Rodrigues A, Gama V. Treatment of type-A aortic dissection using endoprosthesis occurring after coronary artery bypass surgery. Catheter Cardiovasc Interv 2012;80(07): 1099-1104

55 Ronchey S, Serrao E, Alberti V, et al. Endovascular stenting of the ascending aorta for type A aortic dissections in patients at high risk for open surgery. Eur J Vasc Endovasc Surg 2013;45(05): 475-480

56 Spear R, Kaladji A, Roeder B, Haulon S. Endovascular repair of a chronic arch dissecting aneurysm with a branched endograft. Ann Thorac Surg 2013;96(02):e39-e41

57 Bernard Y, Zimmermann H, Chocron S, et al. False lumen patency as a predictor of late outcome in aortic dissection. Am J Cardiol 2001;87(12):1378-1382

58 Yu HY, Chen YS, Huang SC, Wang SS, Lin FY. Late outcome of patients with aortic dissection: study of a national database. Eur J Cardiothorac Surg 2004;25(05):683-690

59 Fattouch K, Sampognaro R, Navarra E, et al. Long-term results after repair of type a acute aortic dissection according to false lumen patency. Ann Thorac Surg 2009;88(04):1244-1250

60 Larsen M, Bartnes K, Tsai TT, et al. Extent of preoperative false lumen thrombosis does not influence long-term survival in patients with acute type A aortic dissection. J Am Heart Assoc 2013;2(04):e000112

61 Kimura N, Tanaka M, Kawahito K, Yamaguchi A, Ino T, Adachi H. Influence of patent false lumen on long-term outcome after surgery for acute type A aortic dissection. J Thorac Cardiovasc Surg 2008;136(05):1160-1166, 1166.e1-1166.e3

62 Park KH, Lim C, Choi JH, et al. Midterm change of descending aortic false lumen after repair of acute type I dissection. Ann Thorac Surg 2009;87(01):103-108

63 Bing F, Rodière M, Martinelli T, et al. Type A acute aortic dissection: why does the false channel remain patent after surgery? Vasc Endovascular Surg 2014;48(03):239-245

64 Hagan PG, Nienaber CA, Isselbacher EM, et al. The International Registry of Acute Aortic Dissection (IRAD): new insights into an old disease. JAMA 2000;283(07):897-903

65 JCS Joint Working Group. Guidelines for diagnosis and treatment of aortic aneurysm and aortic dissection (JCS 2011): digest version. Circ J 2013;77(03):789-828

66 Erbel R, Aboyans V, Boileau C, et al; ESC Committee for Practice Guidelines; The Task Force for the Diagnosis and Treatment of Aortic Diseases of the European Society of Cardiology (ESC). 2014 ESC Guidelines on the diagnosis and treatment of aortic diseases: document covering acute and chronic aortic diseases of the thoracic and abdominal aorta of the adult. Eur Heart J 2014;35 (41):2873-2926

67 Tanaka A, Ishii H, Suzuki S, et al. Influence of false lumen status on the prognosis of acute type a aortic dissection without urgent surgical treatment. J Atheroscler Thromb 2017;24(02):169-175

68 Kitai T, Kaji S, Yamamuro A, et al. Clinical outcomes of medical therapy and timely operation in initially diagnosed type a aortic intramural hematoma: a 20-year experience. Circulation 2009; 120(11, Suppl):S292-S298

69 Song JK, Yim JH, Ahn JM, et al. Outcomes of patients with acute type a aortic intramural hematoma. Circulation 2009;120(21): 2046-2052

70 Kitamura T, Torii S, Horai T, et al. Outcomes of patients who declined surgery for acute Stanford type A aortic dissection with patent false lumen of the ascending aorta. Interact Cardiovasc Thorac Surg 2017;25(01):47-51

71 Ando T, Kobayashi T, Endo H, et al. Surgical treatment or conservative therapy for stanford type a acute aortic dissection with a thrombosed false lumen. Ann Vasc Dis 2012;5(04):428-434 
162 Type-A Dissection in the Current Era Moeller et al.

72 Kurimoto Y, Morishita K, Kawaharada N, Fukada J, Asai Y, Abe T. Initial management of acute type-A aortic dissection with a thrombosed false lumen: a retrospective cohort study. Surg Today 2004;34(08):652-657

73 Zierer A, Voeller RK, Hill KE, Kouchoukos NT, Damiano RJ Jr, Moon MR. Aortic enlargement and late reoperation after repair of acute type A aortic dissection. Ann Thorac Surg 2007;84(02):479-486, discussion 486-487

74 Rylski B, Milewski RK, Bavaria JE, et al. Outcomes of surgery for chronic type A aortic dissection. Ann Thorac Surg 2015;99(01): 88-93
75 Rylski B, Beyersdorf F, Desai ND, et al. Distal aortic reintervention after surgery for acute DeBakey type I or II aortic dissection: open versus endovascular repair. Eur J Cardiothorac Surg 2015;48(02): 258-263

76 Fann JI, Smith JA, Miller DC, et al. Surgical management of aortic dissection during a 30-year period. Circulation 1995;92(9, Suppl): II113-II121

77 Conway BD, Stamou SC, Kouchoukos NT, et al. Improved clinical outcomes and survival following repair of acute type A aortic dissection in the current era. Interact Cardiovasc Thorac Surg 2014;19(06):971-976 